\title{
Erratum to "Performance Evaluation of a Modified SweepSAR Mode for Quad-Pol Application in SAR Systems"
}

\author{
Jung-Hwan Lim ${ }^{1} \cdot$ Jae Wook Lee ${ }^{1, *} \cdot$ Taek-Kyung Lee ${ }^{1} \cdot$ Hyeon-Cheol Lee ${ }^{2}$. \\ Sang-Gyu Lee ${ }^{2} \cdot$ Sang-Burm Ryu ${ }^{2} \cdot$ Seong-Sik Yoon ${ }^{3}$
}

In the paper entitled "Performance Evaluation of a Modified SweepSAR Mode for Quad-Pol Application in SAR Systems (Journal of Electromagnetic Engineering and Science, vol. 20, no. 3, pp. 199-206, 2020)", the Acknowledgments has incorrect information. The correct statement should read.

This work was supported by Korea Environment Industry \& Technology Institute (KEITI) through Development of basic technology for C-band SAR payload Project, performed by Korea Aerospace Research Institute (KARI), funded by Korea Ministry of Environment (MOE) (No. 2019002650002).

${ }^{1}$ Department of Electronics and Information Engineering, Korea Aerospace University, Goyang, Korea.

${ }^{2}$ Satellite Payload Development Division, Korea Aerospace Research Institute, Daejeon, Korea.

${ }^{3}$ Imaging Radar Team, Hanwha Systems, Yongin, Korea.

"Corresponding Author: Jae Wook Lee (e-mail: jwlee1@kau.ac.kr)

This is an Open-Access article distributed under the terms of the Creative Commons Attribution Non-Commercial License (http://creativecommons.org/licenses/by-nc/4.0) which permits unrestricted non-commercial use, distribution, and reproduction in any medium, provided the original work is properly cited.

(c) Copyright The Korean Institute of Electromagnetic Engineering and Science. All Rights Reserved. 